\title{
Revista Clínica de Periodoncia, Implantología y Rehabilitación Oral
}

www.elsevier.es/piro

TRABAJO DE INVESTIGACIÓN

\section{Análisis descriptivo morfoestructural mediante microscopía electrónica de barrido del efecto sobre el esmalte de la técnica de grabado ácido convencional y una nueva técnica de grabado ácido aplicada en 2 tiempos operatorios}

\author{
Marcelo Bader Mattar ${ }^{\mathrm{a}, *}$, Josefa Retamal ${ }^{\mathrm{b}}$ y Asunción Fe Retamal ${ }^{\mathrm{b}}$ \\ a Profesor Asociado, Área de Biomateriales Dentales, Facultad de Odontología, Universidad de Chile, Chile \\ b Docente Meritante, Área de Biomateriales Dentales, Facultad de Odontología, Universidad de Chile, Chile
}

Recibido el 5 de marzo de 2013; aceptado el 2 de agosto de 2013

\section{PALABRAS CLAVE \\ Técnica de grabado ácido convencional; Técnica de grabado ácido modificada; Microestructura del esmalte grabado}

\begin{abstract}
Resumen
Introducción: El grabado ácido total constituye una técnica fiable para asegurar la adhesión en el esmalte. Con una excelente adhesión al esmalte del borde cavo superficial de la preparación cavitaria se podría evitar la aparición de la filtración marginal, es por esto que se desarrolló una técnica que asegure crear un patrón eficaz de grabado en el esmalte, resultando en mayor cantidad de microrretenciones y por lo tanto, en una mejor adhesión micromecánica.

Materiales y métodos: En el presente estudio se utilizaron 5 dientes, todos terceros molares sanos recientemente extraídos, que fueron limpiados y cavitados para luego ser cortados por la mitad y separados en 2 grupos. El grupo A que recibiría la técnica de grabado ácido convencional y el grupo $B$ que recibiría una variación de la técnica en 2 tiempos operatorios. Todas las muestras fueron llevadas al microscopio electrónico de barrido para observar si existen diferencias en la microestructura obtenida en cuanto al esmalte.

Resultados: Se observaron diferencias entre las superficies adamantinas de un mismo diente, al ser grabadas con los diferentes métodos, existiendo un patrón de grabado con mayor definición y porosidad en las muestras sometidas a grabado ácido en 2 tiempos operatorios.

Conclusión: Existen diferencias microestructurales entre las superficies adamantinas obtenidas tras el grabado según la técnica convencional y las obtenidas mediante el grabado en 2 tiempos operatorios.

(c) 2014 Sociedad de Periodoncia de Chile, Sociedad de Implantología Oral de Chile y Sociedad de Prótesis y Rehabilitación Oral de Chile. Publicado por Elsevier España, S.L. Todos los derechos reservados.
\end{abstract}

*Autor para correspondencia.

Correo electrónico: marcelo.bader@gmail.com (M. Bader Mattar).

0718-5391/@ 2014 Sociedad de Periodoncia de Chile, Sociedad de Implantología Oral de Chile y Sociedad de Prótesis y Rehabilitación Oral de Chile. Publicado por Elsevier España, S.L. Todos los derechos reservados. 


\section{KEYWORDS}

Conventional total acid etch technique; Modified total acid etch technique; Etched Enamel microstructure
Descriptive analysis of the enamel microestructure after the conventional and a two-step modified acid etch technique using scanning electron microscopy

\begin{abstract}
Introduction: Total acid etch is a reliable technique for ensuring adhesion to enamel, providing a durable adhesive interface between enamel surface and composite restoration, in order to prevent the development of micro-leakage. A variation of the etching technique was developed to create an effective and regular etching pattern. This could result in large amounts of retentions and higher surface porosity, leading to better micromechanical adhesion.

Materials and methods: A study was conducted on five healthy, recently extracted third molars. They were cleaned and cavitated before being cut in half and separated into two groups. Group A received conventional etching technique and group B received a variation of the technique in a two-step procedure. All samples were observed by scanning electron microscopy (SEM) order to observe the differences in enamel microstructure between both groups.

Results: There were differences between the surfaces of the same tooth when etched using the different methods. There was a pattern with greater definition and porosity in the samples subjected to two-step acid etching.

Conclusion: There where microstructural differences on the enamel surfaces between samples etched by a conventional technique and those using a two-step acid etching. (C) 2014 Sociedad de Periodoncia de Chile, Sociedad de Implantología Oral de Chile y Sociedad de Prótesis y Rehabilitación Oral de Chile. Published by Elsevier España, S.L. All rights reserved.
\end{abstract}

\section{Introducción}

La caries dental es una enfermedad de alta prevalencia que tiene como consecuencia la pérdida de tejido dentario'. El esmalte es un tejido cristalino, microporoso de alta mineralización y de extrema dureza, sin embargo, al ser acelular, avascular y aneuronal su única y particular forma de reaccionar ante cualquier acción física, química o biológica es con pérdida de su fase mineral, cuya magnitud está en relación directa con la intensidad del agente causal ${ }^{2}$.

En caso de generarse una pérdida o falencia de estructuras dentarias, estas deben ser restauradas mediante el uso de materiales restauradores específicos, con el objetivo de recuperar la forma y función perdidas. En la actualidad se suele recurrir a la odontología adhesiva con el fin de no comprometer estructuras dentarias sanas solo para crear cavidades retentivas.

Uno de los aspectos más importantes que se ha de considerar para el éxito de una restauración es el grado de sellado alcanzado en el ámbito de la interfase diente-restauración, ya que la pérdida de la integridad marginal de la restauración suele manifestarse como microfiltración ${ }^{3}$, lo que llevaría al fracaso de la misma.

La microfiltración, que permite el paso de bacterias, fluidos orales e iones entre la pared de la cavidad y la restauración, es uno de los parámetros más importantes de evitar y por lo mismo, constituye uno de los objetivos que se ha de manejar por la odontología adhesiva, principalmente por las secuelas clínicas que acarrearía como son la aparición de caries secundarias, sensibilidad posoperatoria y teñido de la restauración ${ }^{3}$.

La adhesión a esmalte ha sido bien estudiada y suele arrojar valores bastante estables entre diferentes estu- dios $^{4}$. Esto es importante, pues al lograr una excelente adhesión en el esmalte del borde cavo superficial podríamos evitar la aparición de la microfiltración, y es por esto que se han desarrollado diferentes procedimientos que aseguren la creación de un patrón profundo de grabado en el esmalte, resultando en una mayor cantidad de microrretenciones y por lo tanto, en una mejor adhesión micromecánica.

Pero ¿son todas la piezas dentarias igual de susceptibles al grabado ácido? Un diente que ha sido sometido a un régimen de tratamiento con fluoruros tiene un comportamiento muy disímil al de un diente normal, ya que el flúor provoca un cambio en la microestructura cristalina del esmalte optimizándola en cuanto al tipo y calidad de la cristalinidad y a la cantidad de minerales que debieran ser disueltos durante el proceso de grabado en la superficie del esmalte, lo que afectaría a la unión mediante grabado ácido de resinas compuestas y/o sellantes ${ }^{5}$. Asimismo, como resultado del paso del tiempo, con la edad se generan cambios relacionados en la porción orgánica del esmalte cerca de la superficie, que serían los causantes de que el esmalte se transforme en uno más duro y más resistente a la desmineralización ${ }^{6,7}$. Por otro lado, existen diferencias en el patrón de grabado producido en los distintos tipos de dientes, siendo más profundo el obtenido en dientes anterosuperiores ${ }^{8}$. Sin embargo, a pesar de estas diferencias que podrían afectar al resultado del acondicionamiento ácido de las superficies adamantinas, siempre se indica el mismo tiempo de grabado ácido en todas las piezas dentarias, lo que podría tener incidencia en la efectividad del grabado generado sobre estas superficies.

Considerando lo anterior, se desarrolló una nueva técnica de grabado ácido que considera estas diferencias en las piezas dentarias para ser utilizada de manera universal, creando un método de grabado en 2 tiempos operatorios. El presente 
Análisis descriptivo morfoestructural mediante microscopía electrónica de barrido del efecto sobre el esmalte de la técnica de grabado ácido convencional y una nueva técnica de grabado ácido aplicada en 2 tiempos operatorios

estudio propone el grabado ácido en 2 tiempos operatorios, en donde tras exponer el esmalte a la reacción con ácido ortofosfórico durante 10 segundos, es lavado para ser expuesto a un ácido nuevo, durante otros 10 segundos evitando así la autolimitación de la acción del ácido y la decantación de sales que pueden obliterar la superficie adamantina, alterando el grabado generado inicialmente. Al grabar por segunda vez se actúa sobre una superficie preacondicionada, lo que permitiría un mejor patrón de grabado.

De acuerdo con lo anterior, en el presente estudio se buscó observar a través del microscopio electrónico de barrido, el efecto que produce el grabado ácido sobre el esmalte siguiendo la técnica convencional, en donde se graba el esmalte con el mismo ácido durante 20 segundos, comparándola con la técnica propuesta de grabado en 2 tiempos operatorios separados.

\section{Materiales y métodos}

El presente trabajo corresponde a un estudio de tipo descriptivo donde se utilizó la observación como método de investigación. Este se llevó a cabo en el Laboratorio del Área de Biomateriales Dentales del Departamento de Odontología Restauradora, de la Facultad de Odontología de la Universidad de Chile y en el Laboratorio de Microscopía Electrónica CESAT-ICBM de la Facultad de Medicina de la Universidad de Chile.

En el estudio se usó una muestra de 5 piezas dentarias, constituida por molares sanos, macroscópicamente libres de caries, recién extraídos y mantenidos en suero fisiológico. Su recolección se realizó previo consentimiento informado firmado por el paciente donador. Luego se llevó a cabo una limpieza mecánica de cada molar con escobilla suave, agua y curetas Gracey 7-8, marca American Eagle USA, para eliminar los restos de tejidos blandos y sangre que pudieran quedar presentes.

Enseguida se realizaron preparaciones cavitarias, oclusales estandarizadas clase I de $2 \mathrm{~mm}$ de ancho, $3 \mathrm{~mm}$ de largo mesio-distal y $3 \mathrm{~mm}$ de profundidad; para esto se utilizó turbina W\&H modelo Alegra HS serie 30899 y fresas de diamante nuevas: redonda (SS White de 016 ISO 806314001524016 Lot. 201100028596), para abrir la cavidad, y una cilíndrica (SS White de 014 ISO 806314111524014 Lot. 201100020353), para conformar la cavidad.

Se enumeraron las coronas del 1 al 5 y se cortaron las raíces con micromotor y pieza de mano W\&H modelo Alegra $\mathrm{HE}-43$, portadisco y disco de diamante de 0,2 $\mathrm{mm}$ de grosor; luego se seccionó cada pieza dentaria en 2 mitades, teniendo 10 muestras en total. Las mitades palatinas/linguales conformaron el subgrupo $\mathrm{A}$ y las mitades vestibulares conformaron el subgrupo $B$.

Luego, cada muestra se seccionó en sus extremos mesiales y distales con el fin de tener una muestra pequeña y cuadrangular, que finalmente se dispusieron sobre un soporte para que pudieran ser grabadas. Para el grabado ácido se utilizó ácido fosfórico al 37,5\% de Kerr Corporation. Item N. ${ }^{\circ} 31297$, Lot. 3636668.

El procedimiento de acondicionamiento ácido de las estructuras dentarias fue realizado por el mismo operador, siguiendo un protocolo estandarizado en la forma y tiempo de aplicación del ácido, de acuerdo con las siguientes especificaciones.

Las muestras del subgrupo A fueron grabadas siguiendo los siguientes pasos:

1. Se aplicó ácido ortofosfórico en esmalte durante 20 segundos. (Cronómetro marca Casio HS-70W).

2. Se lavó profusamente con agua durante 40 segundos.

3. Se secó el esmalte con aire a través de una jeringa triple.

Las muestras del subgrupo B fueron grabadas siguiendo los siguientes pasos:

1. Se aplicó ácido ortofosfórico en esmalte durante 10 segundos.

2. Se lavó profusamente con agua durante 20 segundos y se secó con aire mediante una jeringa triple.

3. Se aplicó ácido ortofosfórico, en esmalte durante 10 segundos. (Cronómetro marca Casio HS-70W).

4. Se lavó profusamente durante 20 segundos con agua.

5. Se secó el esmalte con aire mediante una jeringa triple.

Una vez grabadas, las muestras fueron llevadas al laboratorio de microscopía electrónica CESAT-ICBM de la Facultad de Medicina de la Universidad de Chile, donde fueron secadas a $37{ }^{\circ} \mathrm{C}$ durante $24 \mathrm{~h}$ con calor seco, para después ser montadas de a pares sobre un soporte circular al cual se adhirieron con tintura de plata y luego fueron metalizadas con paladio-oro $10 \mathrm{~nm}$ de espesor en un sputter marca Polaron, modelo E-500, Reino Unido, 1992.

A continuación, las 10 muestras fueron observadas por un mismo operador debidamente entrenado en el manejo del microscopio electrónico de barrido (Digital Scaning Microscope DSM 940 Zeiss, Alemania, 1990), para lo cual utilizó aumentos sucesivos de 100x, 500x, 3.000x y 5.000x. Se fotografiaron con la cámara Canon EOS REBEL XT con que está provisto el microscopio. Las imágenes obtenidas fueron analizadas para comparar la morfología de la superficie adamantina y ver las diferencias microestructurales existentes tras el grabado obtenido.

Las comparaciones se realizaron entre las mitades del mismo diente tratadas de manera diferente y con el mismo aumento.

\section{Resultados}

Algunas de las imágenes obtenidas en este estudio se muestran a continuación.

En ambas figuras se observan cabezas de prismas de esmalte (C) y luego los prismas a lo largo (L). El grado de desmineralización y porosidad observado en la figura $1 \mathrm{~A}$ es menor a la observada en la figura $1 \mathrm{~B}$, donde se puede contar mayor número de cabezas de prismas, y da una idea de mayor profundidad de esmalte grabado.

En la figura 2A, a mayor aumento, se puede observar un patrón de grabado como punta de lápiz con algunas microporosidades. En la figura 2B se observa un patrón de grabado tipo 2, con abundantes microporosidades y con una delimitación más nítida de las cabezas de los prismas, lo que significaría un mejor sustrato retentivo para el adhesivo. 


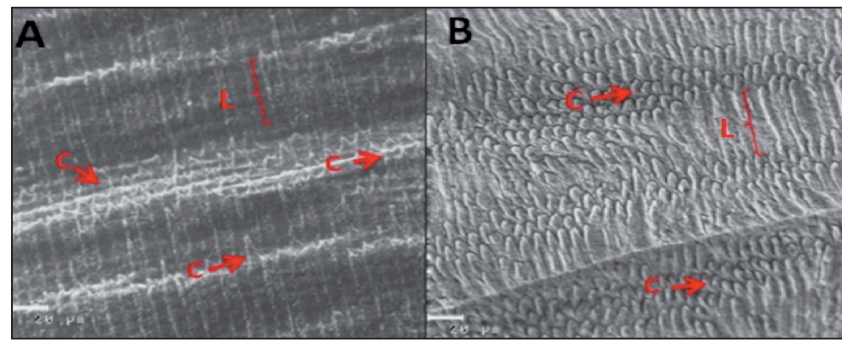

Figura 1. Imágenes de microscopía electrónica de barrido correspondientes al esmalte de la superficie interna de la pared lateral de una cavidad tras ser grabada con ácido ortofosfórico utilizando $(A)$ técnica convencional y $(B)$ técnica de grabado en 2 tiempos operatorios (aumento de 500x).

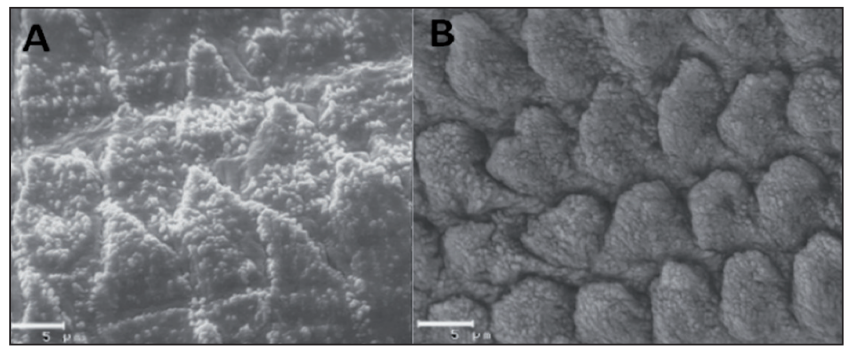

Figura 2. Imágenes de microscopía electrónica de barrido correspondientes a las cabezas de los primas de esmalte tras grabado ácido realizado mediante $(\mathrm{A})$ técnica convencional y (B) técnica en 2 tiempos operatorios (aumento $3.000 x)$.

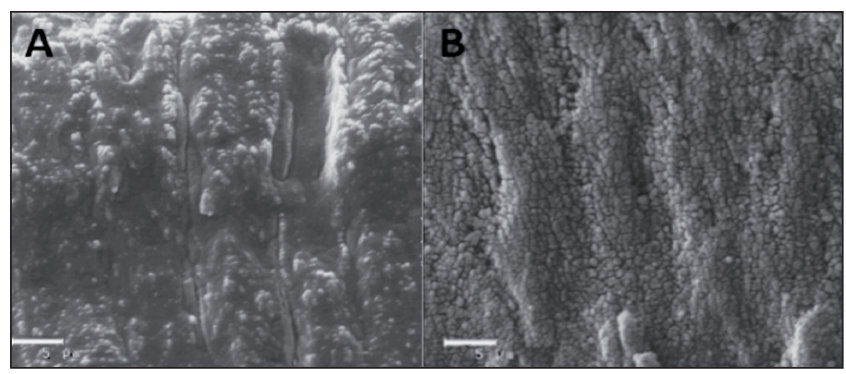

Figura 3. Imágenes de microscopía electrónica de barrido correspondientes a esmalte de la pared lateral de la superficie cavitaria, observándose prismas de manera longitudinal tras grabado ácido realizado mediante $(\mathrm{A})$ técnica convencional y $(B)$ técnica en 2 tiempos operatorios (aumento $3.000 x)$.

Confirmando lo observado en las fotografías anteriores, se puede establecer que el grabado en 2 tiempos operatorios permite lograr un cambio micromorfológico más sustantivo en los prismas del esmalte, dejando un patrón de grabado con surcos más marcados entre los prismas y creando mayor cantidad de microporosidades en su superficie.

En ambas imágenes queda de manifiesto la pérdida del esmalte interprismático, exponiendo los prismas y aglomeraciones de cristales de hidroxiapatita. En la figura $3 \mathrm{~A}$ se ven aglomeraciones de cristales separadas a lo largo del

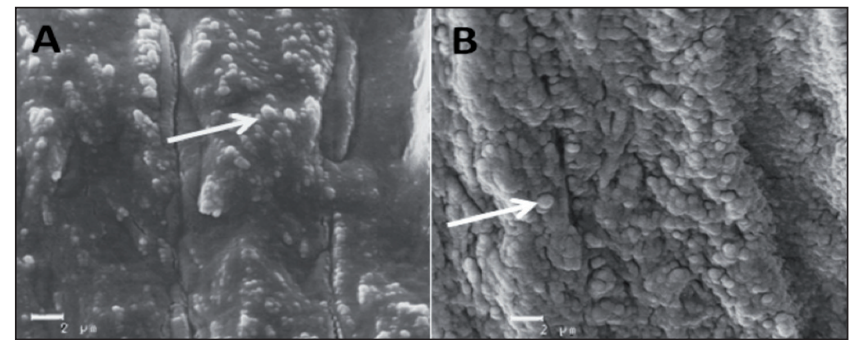

Figura 4. Imágenes SEM correspondientes a esmalte de la pared lateral de la superficie cavitaria, observándose prismas de manera longitudinal tras grabado ácido realizado mediante $(A)$ técnica convencional y $(B)$ técnica en 2 tiempos operatorios (aumento 5.000x).

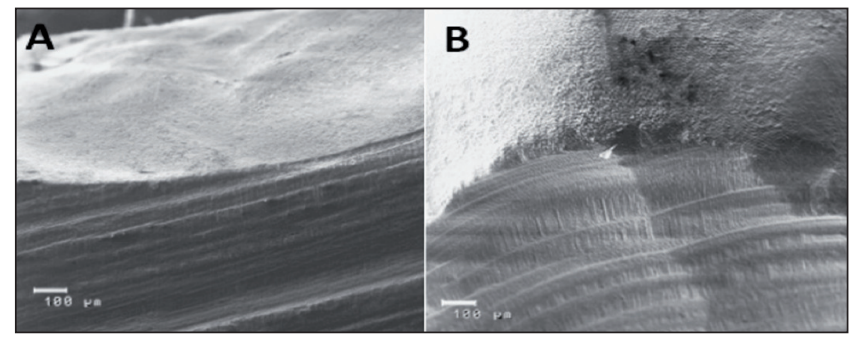

Figura 5. Imágenes de microscopía electrónica de barrido correspondientes al borde cavo superficial de una cavidad tras ser tratado con grabado ácido mediante $(\mathrm{A})$ técnica convencional y (B) técnica en 2 tiempos operatorios (aumento de 100x).

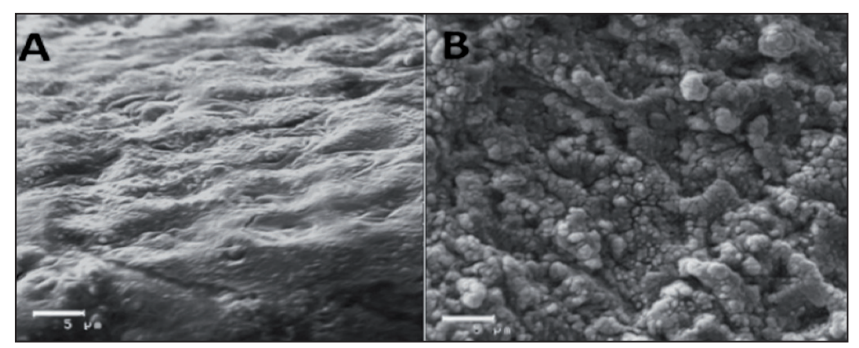

Figura 6. Imágenes de microscopía electrónica de barrido correspondientes a la superficie no instrumentada de una pieza dentaria tras ser tratada con grabado ácido realizado mediante $(A)$ técnica convencional y $(B)$ técnica en 2 tiempos operatorios (aumento de 3.000x).

prisma, mientras que en la figura $3 \mathrm{~B}$ se observan una al lado de la otra, mostrando una exposición homogénea.

En ambos casos, lo señalado con la flecha blanca corresponde a una aglomeración de cristales de hidroxiapatita que ha quedado expuesta tras el grabado ácido. La figura $4 \mathrm{~B}$ presenta mayor densidad de estas aglomeraciones expuestas.

En la figura 5 se observa que la superficie tratada con la técnica de grabado ácido en 2 tiempos operatorios se muestra más irregular que la superficie grabada según la técnica convencional; esto se hace evidente al observar luego, en mayor aumento, la morfología de estas superficies en la figura 6. 
Análisis descriptivo morfoestructural mediante microscopía electrónica de barrido del efecto sobre el esmalte de la técnica de grabado ácido convencional y una nueva técnica de grabado ácido aplicada en 2 tiempos operatorios

En la figura 6 se puede observar que entre ambas superficies se aprecian diferencias en el grado de porosidad alcanzado, siendo mayor el obtenido con la técnica de grabado ácido doble. En la figura $6 \mathrm{~A}$ se logra una leve textura sobre la superficie, similar a un patrón de grabado tipo 4 , mientras que en la figura 6B se observan mayor cantidad de irregularidades.

\section{Discusión}

La adhesión de los materiales de restauración al tejido dentario constituye un constante desafío para la odontología con el fin de lograr encontrar una estrategia que permita una mayor longevidad de las obturaciones.

Desde hace años, la técnica de grabado ácido total constituye una forma segura y efectiva para lograr adhesión en el esmalte, sin embargo, aún no se logra idear una manera de evitar la microfiltración como puerta de entrada de microorganismos que deriva en caries secundaria.

El presente estudio intentó conciliar la idea de que cada pieza dentaria tiene distintos grados de suceptibilidad a la desmineralización por grabado ácido, ejemplo de esto son los distintos grados de profundidad de patrón de grabado entre piezas sanas y piezas con fluorosis, entre piezas jóvenes versus piezas seniles y los distintos tipos de diente entre $s i^{5-9}$. Por lo tanto resultaría altamente efectivo poder encontrar una técnica donde el patrón de grabado sea el más adecuado para lograr de manera segura una alta adhesión.

Como resultado del presente estudio, se observaron diferencias microestructurales entre las superficies de un mismo diente que fueron acondicionadas con las distintas formas de grabado ácido evaluadas: la nueva técnica propuesta de grabado ácido adamantino en 2 tiempos operatorios secuenciales, y la técnica convencional de grabado ácido en un solo tiempo operatorio.

En todas las muestras observadas en el microscopio electrónico de barrido, el patrón de desmineralización sobre las piezas tratadas con la técnica de grabado convencional mostraron una superficie con exposición dispersa de aglomeraciones de cristales, mientras que aquellas tratadas con el doble grabado ácido mostraron una continua exposición de estas. De acuerdo con ello, la estructura micromorfológica observada muestra que, la nueva técnica propuesta da una imagen de un mejor patrón de grabado, con una adecuada exposición de los prismas y con una superficie más irregular, lo que beneficiaría el proceso de adhesión.

Se pueden inferir similitudes entre este estudio y el realizado por Lima A et al. en donde el patrón de grabado obtenido es mucho más profundo al utilizar grabado ácido total y el uso posterior de un adhesivo autograbante que cualquier patrón obtenido utilizando cualquiera de estos 2 procedimientos por separado. Esto se atribuye a la existencia de un doble contacto de la superficie al efecto de ácido: primero ácido ortofosfórico y luego los ácidos del "primer" acídico autograbante. Asimismo, la fuerza de adhesión fue mayor en el esmalte que había sido sometido a grabado ácido durante 15 segundos y luego a un sistema autograbante ${ }^{10}$.

De esta misma manera, muchos otros estudios demuestran que al grabar previamente el esmalte con ácido orto- fosfórico y luego utilizar adhesivo de autograbado, la microfiltración es significativamente reducida ${ }^{11,12}$ y la fuerza de adhesión aumenta sustancialmente ${ }^{13-17}$.

Las diferencias observadas en el presente estudio se podrían atribuir a que tras la exposición del esmalte a la acción del ácido en un primer tiempo se logra preacondicionar la estructura adamantina, generando un pregrabado de la misma, lo que permite que al ser esta atacada nuevamente con ácido, se genere una mayor facilidad para generar una desmineralización selectiva y más efectiva de los prismas, originando los patrones de grabado observados. Del mismo modo, al hacer el grabado en un solo tiempo operatorio, es decir durante 20 segundos seguidos, desde el momento en que el ácido inicia su acción, se comienza a generar una migración de cationes de calcio desde los cristales de hidroxiapatita, los cuales entrarán en solución formando sales con los aniones fosfatos que quedaron luego de su disociación de los protones que atacaron la superficie dentaria. Lo anterior va a producir un alza en el $\mathrm{pH}$ y por lo mismo una disminución de la acción de grabado. Esto se evitaría al cambiar el gel de ácido y aplicar una nueva solución en gel, que comenzaría su acción con su pH original y atacando una superficie ya pregrabada.

Como se señaló, cuando comienza la acción de grabado, los cationes de calcio que salen del esmalte removidos por la acción de los protones que ingresan a él, por su carga eléctrica se van a unir a los aniones fosfatos del ácido que quedaron en la superficie externa, entrando en solución con ellos y formando fosfato de calcio. A medida que el proceso avanza, esta solución podría sobresaturarse y reprecipitar estas sales en la superficie adamantina ocluyendo en parte el patrón de grabado generado, como pudo observarse en las diversas imágenes presentadas con anterioridad. Este fenómeno, conocido como efecto autolimitante, restringe, en caso de aparecer, la efectividad del grabado del ácido. De acuerdo con lo anterior, al grabar en un solo tiempo operatorio de 20 segundos, dependiendo del ácido utilizado, se corre el riesgo de que se alcance su sobresaturación durante ese tiempo y se produzca la reprecipitación se sales de fosfato de calcio ocluyendo las porosidades generadas, mientras que por el contrario, al cambiar el ácido a los 10 segundos, y lavar profusamente la superficie dentaria, se eliminará dicho riesgo ya que no se alcanzarían los niveles de sales de fosfato de calcio suficientes como para que lleven a su precipitación, y al mismo tiempo, el lavado profuso eliminará todas aquellas que pudieran haberse precipitado dejando así la superficie más apta para una nueva acción de acondicionamiento ácido. Al hacerlo en 2 tiempos operatorios, el primer ácido actúa pregrabando, dejando un sustrato más susceptible de volver a grabar por un ácido nuevo, todo lo cual resulta en un patrón de grabado más nítido y regular, lo que significaría un mejor sustrato retentivo para el adhesivo.

\section{Conclusiones}

De acuerdo con la metodología utilizada en este estudio y a partir de los resultados obtenidos se puede concluir que se aprecian diferencias microestructurales evidentes entre las superficies adamantinas tratadas con ambos procedimien- 
tos de grabado: el convencional actual aplicado en un solo tiempo operatorio de 20 segundos y la técnica modificada en 2 tiempos sucesivos de 10 segundos cada uno. Aquellas piezas dentarias en las que se utilizó el grabado ácido en 2 tiempos operatorios presentaron un patrón más definido y regular y con mayor cantidad de microporosidades que el obtenido con la técnica de grabado ácido convencional. Lo anterior se logró tanto en superficies no instrumentadas como en las que forman parte de las preparaciones cavitarias, mostrando patrones que se condicen con los patrones convencionales de grabado adamantino.

De acuerdo con lo anterior, y a la luz de las imágenes observadas, el hecho de aplicar el nuevo procedimiento de grabado propuesto permitiría generar un mejor sustrato para la adhesión en el borde cavo superficial de la preparación cavitaria, con el beneficio de permitir así lograr un mejor sellado marginal a este nivel, y por lo mismo, una interfase adhesiva que evite la filtración marginal, aumentando la longevidad de las restauraciones adhesivas directas.

\section{Conflicto de intereses}

Los autores declaran que no tienen ningún conflicto de intereses.

\section{Bibliografía}

1. Ministerio De Salud, Chile. Análisis de Situación Salud Bucal [Acceso 31 Mar 2012]. Disponible en: http://web.minsal.cl/ portal/url/item/9c81093d17385cafe04001011e017763.pdf

2. Henostroza G. La adhesión en la odontología, 1. ${ }^{a}$ ed. Curitiba, Brasil: Editorial MAIO; 2003. p. 43-51, 72-81, 101-8, 114-31.

3. Kihn PW, Spanganberg PA, Von Fraunhofer JA. The role of cavity preparation and conditioning in the leakage of restorations. $J$ Adhes Dent. 2004;6:287-91.

4. Lopes GC, Thys DG, Klaus P, Oliveira GM, Widmer N. Enamel acid etching: a review. Compend Contin Educ Dent. 2007;28:1824; quiz 25, 42.

5. Cheong Y, Choi S, Jung Kim S, Park H. Nanostructural effect of acid-etching and fluoride application on human primary and permanent tooth enamels. Materials Science and Engineering C. 2012. Article in press. doi: $10.1016 /$ j.msec. 2012.02 .030

6. Uysal T, Amasyali M, Ozcan S, Sagdic D. Demineralization properties of newly erupted and mature premolars around orthodontic brackets: an in vivo study. Am J Orthod Dentofacial Orthop. 2010;137:582.e1-6; discussion 582-3.

7. Bhaskar SN. Orban's oral histology and embryology. 9th ed. St Louis: C.V. Mosby; 1980. p. 46-106.

8. Hobson RS, McCabe JF, Hogg SD. Bond strength to surface enamel for different tooth types. Dent Mater. 2001;17:184-9.

9. Torres-Gallegos I, Zavala-Alonso V, Patiño-Marín N, MartinezCastañón GA, Anusavice K, Loyola-Rodríguez JP. Enamel roughness and depth profile after phosphoric acid etching of healthy and fluorotic enamel. Aust Dent J. 2012;57:151-6.

10. Lima AF, Da Silva VB, Soares GP, Marchi GM, Aguiar FH, Lovadino $J R$. Influence of previous acid etching on interface morphology and bond strength of self-etching adhesive to cavosurface enamel. Eur J Dent. 2012;6:56-62.

11. Brackett MG, Brackett WW, Haisch LD. Microleakage of Class V resin composites placed using self-etching resins: effect of prior enamel etching. Quintessence Int. 2006;37:109-13.

12. Manuja N, Nagpal R, Chaudhary S. Bonding efficacy of 1-step self-etch adhesives: effect of additional enamel etching and hydrophobic layer application". J Dent Child (Chic). 2012;79: 3-8.

13. Miguez PA, Castro PS, Nunes MF, Walter R, Pereira PN. Effect of acid-etching on the enamel bond of two self-etching systems. J Adhes Dent. 2003;5:107-12.

14. Erhardt MC, Cavalcante LM, Pimenta LA. Influence of phosphoric acid pretreatment on self-etching bond strengths. J Esthet Restor Dent. 2004;16:33-40; discussion 41.

15. Van Meerbeek B, Kanumilli P, De Munck J, Van Landuyt KL, Lambrechts P, Peumans M. A randomized controlled study evaluating the effectiveness of a two-step self-etch adhesive with and without selective phosphoric-acid etching of enamel. Dent Mater. 2005;21:375-83.

16. Van Landuyt KL, Kanumilli P, De Munck J, Peumans M, Lambrechts P, Van Meerbeek B. Bond strength of a mild selfetch adhesive with and without prior acid-etching. J Dent. 2006;34:77-85.

17. Lührs AK, Guhr S, Schilke R, Borchers L, Geurtsen W, Günay $\mathrm{H}$. Shear bond strength of self-etch adhesives to enamel with additional phosphoric acid etching. Oper Dent. 2008;33: 155-62. 